\title{
Transfer of surgical knowledge: a continuous challenge
}

\section{A cardiac surgeon's perspective on transfer of surgical knowledge}

\section{Marko Turina}

University Hospital, Zürich, Switzerland

Address for correspondence:

Prof Marko Turina,

Haldenbach 18

8091

Zurich

Switzerland

Email:

marko.turina@usz.ch

Cardiac surgery is a relatively new surgical discipline. In First World countries the origin of cardiac surgery can be traced to pioneering work done in the 50s and 60s; it became routine in the 70s and 80s. After an explosive growth, mostly due to development of coronary surgery, the numbers of procedures are remaining stable or even declining, due to rapid development of invasive cardiology. Today, cardiac surgery is a standard part of surgical services in most of major hospitals, but it admittedly needs a large infrastructure and substantial financial investment. Training in cardiac surgery is also long, extending to at least two to five years after finishing general surgical training. It is not surprising that cardiac surgery is at an advanced level in first world countries with substantial gross national products. Less than adequate development of cardiac surgery can be observed in the second world countries and, it is even worse in the third world countries where gross national products are not adequate to support high technology hospitals and assure proper surgical training. Indeed, there is a linear logarithmic relation between gross national product and overall number of practicing cardiothoracic surgeons in various areas of the world. ${ }^{(1)}$

In developing countries, there is an obvious need for high-level medical care, at least in some of the major hospitals. Due to various forms of international assistance, many countries possess one or several modern hospitals, sometimes even with proper equipment, but they are rarely used to satisfaction. Reasons for this disappointing

\section{ABSTRACT}

Cardiac surgery is an expensive method of treatment, and the population's need will probably never be completely met, even in developed nations, as reflected by recent discussions about limits of care in aged and polymorbid patients. The problem is, of course, much more acute in less developed and developing nations, and their population needs are near impossible to cover. Major surgical associations have only limited funds available, and the transfer of knowledge remains the most efficient way of improving the level of surgical education in these countries, therefore improving care of cardiosurgical patients. SAHeart 201 1; 8:130-131

development are well known: there is a constant problem of staffing, especially in intensive care and in the operating room; the salaries are inadequate, and there is a substantial brain drain to Western Europe or North America, with better working and living conditions. Specialised equipment cannot be kept in working order, adequate diagnostics are not available, and often there is a substantial political interference in the management of the hospitals.

What can be done to improve this unsatisfactory situation? Presently, five different methods of international assistance in the field of cardiac surgery can be observed:

\section{Developmental assistance by Western Governments}

This is really a customary developmental help offered by European and North American governments, which usually involves construction of a hospital, provided with proper diagnostic and medical equipment. Typically, there is no further effort involved, primarily in staffing the hospital, which is considered the task of local authorities. Sometimes, these projects can be successful, but very often they fall short of expectations, are poorly utilised and left to decay.

\section{Assistance by Non-Governmental Organisations (NGOs)} There is a whole group of various charities involved in construction and management of specialised hospitals in the field of cardiac 
cardiothoracic, or cardiovascular surgery. This work is performed very efficiently by organisations such as Chain of Hope, (2) Chaîne de l'Espoir( ${ }^{(3)}$ and Emergency. ${ }^{(4)}$ Their hospitals are offering high-level medical care and cardiac surgery, mostly to children; their work is based on periodic visits by trained teams from supporting countries. Actual training of local surgeons and their staff is - with rare exceptions - a lesser priority in these efforts. Financial needs of these projects are substantial, and annual budget of NGOs committed to such work lies is double digit of millions. Furthermore, there is constant effort to keep the centre functioning all the time, and finding staff willing to transfer temporarily to such an institution, working often under strenuous conditions in less developed nations. Still, these charities must be credited in bringing cardiac surgery to many nations where such a treatment was never possible before, like Equatorial Africa, or the Middle East and Asia.

\section{Individual surgical visits}

Periodic visits by individual surgeons or - what is practiced more often - by a complete surgical team, which arrive in a particular hospital for a period of several days or weeks, is becoming very popular. This is an efficient method of surgical assistance and gives good surgical results, especially when a trained team of cardiologists, intensivists and anaesthetists accompanies the surgeon in his activities at a given hospital. It is also an expensive form of surgical assistance, given the substantial cost of transporting eight to ten people and their equipment to a distant part of the world and keeping them functioning for a week or more. Strong support of the surgeon's institution is necessary to permit the whole team to spend extended periods away from their place of work.

\section{Payment for care of patients in an European or North American institution}

The simplest and indeed the oldest method of international assistance lies in transporting patients - very often children - to a special institution in a developed country, where the optimal surgical care can be provided. This is by far the best method, as far as the results are concerned, and transportation cost is small, but the treatment is usually very expensive, given the high hospital costs in the Western World. Educational effort is nil: none of the local surgeons, cardiologists or anaesthetists profit from such travel.

\section{Transfer of knowledge}

The final method of surgical assistance is the transfer of knowledge, which is presently practiced by the European Association for Cardiothoracic Surgery (EACTS). In the past, EACTS was repeatedly approached from various countries and surgeons to assist them in developing their cardiac programme. Therefore, Council of the
EACTS has formulated its position in the field of international assistance. ${ }^{(5)}$ In summary, EACTS stated that it cannot (and is financially unable to) accept responsibility for running of the cardiothoracic centre in a third world or in a developing nation. In the nineties, limited financial assistance was extended to some surgeons from Eastern Europe, who were not able to travel and visit advanced institutions. Various funds were made available to a particular surgeon for limited period, to enable him to visit one or several institutions in Western Europe. Obvious drawback of this system was the inability to reach a larger population of surgeons in need of additional education. Therefore, EACTS has introduced the system of teaching courses, where a curriculum of advanced surgical procedures is being demonstrated by leading experts, accompanied by lectures and practical exercises. Recently, such courses are being offered outside of Europe, and a highly successful EACTS course was organised last year by Francis Smit at the University of Bloemfontein, and is planned in 2011. Similar courses were given in Riyadh, Saudi Arabia, during annual meetings of Saudi Heart Association.

Following extended discussion with the membership, EACTS council has concentrated on the transfer of knowledge as primary method of international assistance. In addition to international courses, system of visiting scholarships was introduced, enabling younger surgeons a visit in an advanced centre in Western Europe, to further their education. Additionally, EACTS School was established in Bergamo, Italy, offering three levels of surgical education in cardiac and pulmonary surgery. ${ }^{(6)}$ This school became very popular and several hundred younger surgeons have participated in the courses, many of them finishing with a European Board of Cardiothoracic Surgery examination. Educational courses are now being expanded into endovascular and robotic thoracic surgery. In future, EACTS intends to place major emphasis on this method of international assistance, which is intended to develop local surgical facilities to a high Western standard by improving the knowledge of surgical staff, who do not have to resort to expensive travel to learn the newest developments of our profession.

\section{REFERENCES}

I. Turina MI. European Association for Cardio-Thoracic Surgery: carrying the torch. Eur J Cardiothoracic Surg 2002;22(6):857-63.

2. Chain of Hope http://www.chainofhope.org/.

3. La chaine de l'espoir http://www.chainedelespoir.org/.

4. Emergency http://www.emergency.it/history.html.

5. Turina MI. (2008) EACTS position on the international assistance in the field of cardio-thoracic surgery. http://www.ctsnet.org/doc/l 1039.

6. EACTS School http://www.eacts.org/content/eacts-school-general-information. 